\title{
A ESCOLA COMO MICROUNIVERSIDADE NA EDUCAÇÃO SECUNDÁRIA EM CUBA
}

\author{
MARIA DO CARMO LUIZ CALDAS LEITE \\ Professora do Centro de Ciências Exatas da Universidade Católica de Santos \\ marialcl@terra.com.br
}

\begin{abstract}
RESUMO
O artigo analisa o processo de transformação desencadeado nas escolas secundárias básicas em Cuba, que atendem alunos das $7^{a}, 8^{a}$ e $9^{a}$ séries. Na busca de soluções para os problemas que afetavam essas escolas, em 200 I, um coletivo de professores dos Institutos Superiores Pedagógicos das diferentes províncias do país implementou a formação de professores generalistas integrais de modo a torná-los capazes de ministrar todas as disciplinas, exceto Inglês e Educação Física, a grupos de 15 alunos. O recorte do estudo prioriza a formação do professor generalista integral, considerando o contexto do movimento de universalização do ensino superior em curso, o qual reestrutura, em todo o país, os Institutos Superiores Pedagógicos e as escolas básicas, estas tratadas como microuniversidades. O percurso metodológico fundamenta-se em abordagem qualitativa do tipo etnográfico, com base em referências fornecidas por Marli André. Destacamse as pesquisas de Carlos Rojas Arce e de Lisardo García Ramis no embasamento teórico da investigação.

EDUCAÇÃO EM CUBA - ESCOLA SECUNDÁRIA - REFORMA EDUCACIONAL
\end{abstract}

\begin{abstract}
THE SCHOOL AS A MINI-UNIVERSITY IN SECONDARY EDUCATION IN CUBA. The article analyses the transformation process introduced into basic secondary schools in Cuba that handle students who are in the $7^{\text {th }}, 8^{\text {th }}$ and $9^{\text {th }}$ grades. Searching for solutions for the problems that were affecting these schools, in 2001, a group of teachers from all the countries Institutos Superiores Pedagógicos - Schools of Education - implemented a complete generalist teachers training, that made them able for teaching all disciplines, except English and Physical Education to groups of 15 students. The study focuses the complete generalist teachers training as part of the on going movement for universalizing graduate high level education, which restructures the Institutos Superiores Pedagógicos and basic schools nationwide, considering these ones as though they were mini-universities. The methodology of the study is based on a qualitative ethnographic approach and founded upon references supplied by Marli André. In this particular
\end{abstract}

Síntese de pesquisa original vinculada à dissertação de mestrado (Leite, 2006), sob orientação da Profa Dra. Angela Maria Martins. 
area, the research works of Carlos Rojas Arce and Lisardo García Ramis stand out, constituting the basis of the present investigation.

EDUCATION IN CUBA - SECONDARY SCHOOL - EDUCATIONAL REFORM

Este texto vincula-se à pesquisa sobre o processo de formação do professor generalista integral - PGI - para a educação secundária básica em Cuba - ESB -, destinada aos alunos, entre 12 e 14 anos, das $7^{\mathrm{a}}$, 8 $8^{\mathrm{a}}$ e $9^{\mathrm{a}}$ séries, dentro do projeto em curso no sistema de ensino cubano, a partir de $200 \mathrm{I}$. A investigação destaca que, cada vez mais, o locus de discussão dos saberes constituintes da docência e das especificidades da ação educativa a ser privilegiado é a própria escola, além de contribuir para o entendimento de novos vínculos entre o trabalho e a educação. As reflexões apresentadas incidem sobre as possibilidades decorrentes do ato de deslocar a formação de professores da universidade para as salas de aula da educação básica.

As causas que induziram as mudanças na formação docente foram desencadeadas no momento histórico chamado Período Especial, que teve início encetado em Cuba em 1991, com a queda dos regimes socialistas no Leste Europeu, mas as transformações no campo político-social na llha estão também influenciadas por inúmeros fatos recentes, sem um contexto sedimentado que permita alusões conclusivas.

O percurso metodológico da pesquisa fundamentou-se em uma abordagem qualitativa do tipo etnográfico, no sentido proposto por André (2004), caracterizado por esquema aberto, que permitiu transitar entre a observação e a análise, entre a teoria e a empiria. A participação em inúmeros encontros educacionais realizados na capital e em diversas províncias de Cuba, propicioume fortalecer elos com a educação cubana e compreender melhor as situações vivenciadas no país. Da frequência aos institutos superiores pedagógicos ISPs - e às escolas extraí significativos elementos. Entretanto, o contato com os docentes da escola básica', as famílias e as organizações de massa, em viagens de retorno à Ilha, entre 2002 e 2006, possibilitou-me formular caminhos para aprofundar as análises acerca dos processos educacionais em Cuba.

I. Na terminologia cubana, os professores das escolas pré-primárias, primárias e secundárias básicas são chamados maestros, e têm uma formação generalista. Assim como nos demais países de língua espanhola, o termo professor passa a ser utilizado quando o docente recebe formação para lecionar disciplinas especí cas, como a Matemática, a História etc. 


\section{CUBA: ANTECEDENTES HISTÓRICOS}

Os estudos da sociedade cubana, formada por retalhos de diferentes origens e culturas, mostram que ao desenvolvimento de uma forte oligarquia, submissa aos signos da aristocracia ibérica, é possível relacionar a revolução agrícola que conduziu o país, no século XIX, à posição de primeiro produtor mundial de açúcar. Entretanto, como fator de emancipação, a escola foi, durante a colonização, notadamente um privilégio da classe média urbana e branca, marcada por alta seletividade.

A cubanía - consolidação da nacionalidade de raiz afro-espanhola e de vocação latino-americana - promoveu os combates pela independência, iniciados em 1868. Após trinta anos de luta, o poder norte-americano interveio em Cuba, impondo ao país amarga experiência, com a chamada Emenda Platt que oficializou o direito a intervenções. A ocupação estendeu-se até 1902 , consolidando a reorganização do sistema em razão de interesses neocoloniais. A influência estrangeira significou a interrupção, entre outras questões, do legado pedagógico de pensadores cubanos dos séculos anteriores, entre eles o ideólogo independentista Félix Varela ( 1788- 1853), pioneiro ao assumir entre os educadores cubanos uma atitude radicalmente revolucionária, pois, mais do que demandas imediatas, defendia que "estudar não é devorar livros; é preciso compreender e meditar" (Buenavilla Recio, 1995, p.89).

A escola em Cuba não pode ser entendida sem menções à obra de José Martí ( I 853- | 895), que ultrapassou os limites da corrente positivista na América Latina e as fronteiras do utilitarismo, "caricaturas de cópias de outras latitudes” (Chávez Rodríguez, 1996, p.36). No seu referencial teórico, que evoluiu historicamente, o processo dialético das categorias pedagógicas destaca a relação entre educar e emancipar. Para Martí (1975, t.8, p.288), "ser culto é o único modo de ser livre".

Como estudioso do ensino nos países de continente americano, Martí elaborou um pensamento pedagógico que constitui, até hoje, "paradigma para a educação de nossos povos" (Buenavilla Recio, 1995, p.72), o qual pode ser assim resumido: educação laica: como direito e dever de todos, assegurando a liberdade de consciência do professor e do aluno; educação científica e politécnica: o ensino das ciências e a educação para o trabalho constituíam princípios básicos; educação para a vida: a finalidade era educar o homem para seu momento e circunstância históricos. 
Em 1953, Cuba era tipicamente um país neocolonial marcado por sombria desatenção aos serviços educacionais. De acordo com o Ministério da Educação (Cuba, 1999, p.9), apenas 56,4\% das crianças frequentavam a escola. Para formar professores, havia seis escolas normais oficiais e três faculdades de educação, com mais de meio milhão de crianças sem escola e um milhão de analfabetos. A partir de 1959, foram promulgadas medidas, modificando de forma radical as estruturas com a criação das bases do modelo que intentava transformar a saúde, a educação e a cultura em direitos de todos. Uma das metas mais ambiciosas foi a erradicação do analfabetismo em 1961. Na campanha de alfabetização, participaram 100 mil estudantes, 13.016 operários, 120.632 alfabetizadores populares e 34.772 professores, o que possibilitou a criação de documentários e análises de interessados em compreender as razões do seu sucesso. $\bigcirc$ objetivo maior foi conseguido: tirar a população da inércia habitual, transformando antigos traços culturais marcados pela expectativa em relação à ação paternalista das autoridades (Machado, 199|). Nas distintas etapas do processo revolucionário cubano, o governo recorreu à política de formação intensiva, com a incorporação de professores à prática.

No final do século passado, Cuba passou por um período complexo, permeado por dificuldades, em razão do desmoronamento do campo socialista, com o qual o país mantinha relações econômicas que alcançavam o percentual de 85\% das importações e exportações. Em 1991, iniciaram-se reformas visando acelerar a exploração de petróleo, o recebimento legal de divisas provenientes de familiares residentes no exterior e a procura de novos mercados, mas, ainda assim, os custos sociais do agravamento da crise logo vieram à tona. $\bigcirc$ aparecimento de grupos em desvantagem social levou, no final da década de 80, ao incremento de processos de socialização de risco em que o contexto familiar contribuía para estimular inadequadamente a criança. Castro Alegret (2005) caracteriza o conceito operativo de desvantagem social, que afeta as condições de vida do menor e seu desenvolvimento, como constituído prioritariamente por: pais alcoólatras, isolados socialmente ou com problemas psiquiátricos; famílias com condutas relacionadas à delinquência, prostituição, abandono dos menores e problemas frequentes com a polícia; habitação deficitária quanto à limpeza e salubridade; cuidados médicos unicamente em situações de risco, e dinâmica familiar conflituosa. A sociedade cubana não escapou às aceleradas transformações que têm influenciado a vida familiar ocorridas no 
mundo, marcadamente as questões relativas à autonomia da mulher, à redução da fecundidade e às mudanças no relacionamento conjugal.

Matizada pelo Período Especial, na década de 90, a escola apresentava lacunas na formação de indivíduos verdadeiramente motivados à prática laboral. Esse fenômeno atingiria, particularmente, a geração jovem nascida após a Revolução, sem memória existencial do passado, acostumada a receber os serviços estatais com pouco esforço pessoal. Paradoxalmente, as conquistas como a garantia de pleno emprego, os serviços médicos e educacionais gratuitos e o baixo preço das tarifas de transporte, enfim, as políticas de distribuição mais equitativa de bens sociais foram consideradas fontes responsáveis, em grande parte, pela acomodação e pela indisciplina nos locais de trabalho.

\section{A FORMAÇÃO DO PROFESSOR GENERALISTA INTEGRAL}

O sistema educacional cubano, integrado pela escola, família e por organizações de massa dentro de um conceito dialético de formação do homem, deixa de corresponder integralmente às exigências para o novo milênio quanto à formação de valores como autodisciplina e responsabilidade. Considerando a deterioração dos princípios identificados com a ética da Revolução, especialmente a solidariedade e o coletivismo, houve múltiplos impasses, não restritos exclusivamente aos jovens, no processo que deveria responder às demandas emergentes em escala internacional e, ao mesmo tempo, adequar-se às complexas condições internas, resultantes do Período Especial. Apenas com lições não se forjariam novas consciências, uma vez que a necessidade de participação dos jovens no esforço coletivo se fazia mais presente a cada dia.

Os estudos elaborados pelo Instituto Central de Ciências Pedagógicas ICCP - , a partir de 1999, reconheceram que os impactos das transformações sociais e econômicas no início deste século suscitavam a reavaliação do papel da escola e dos professores. Na busca de um modelo para as escolas secundárias básicas que fosse resultado de pesquisas, procedeu-se à caracterização desse nível de ensino, na qual se revelavam tanto os avanços nos últimos anos, como as dificuldades. Com base nas discussões entre os coletivos escolares e os pesquisadores do ICCP, foram construídos referenciais com vistas a fundamentar uma mudança mais profunda no ensino médio de formação geral, uma vez que nele persistiam manifestações tradicionalistas (Rojas Arce, 2002). 
Como esclarece Díaz Fuentes (2005), o problema que deveria ser resolvido, no âmbito do sistema nacional de educação, seria transformar a escola secundária básica, considerada o elo mais fraco das instituições escolares cubanas, de acordo com uma concepção das contradições que determinariam a necessidade de efetuar as mudanças. Conforme Rojas Arce (2005), no período letivo de 1999-2000, a direção do Ministério da Educação, como resposta aos problemas que se manifestavam na ESB, empreendeu um processo de mudanças priorizando o fortalecimento da interdisciplinaridade.

No debate mundializado sobre as reformas educacionais, frequentemente são enfatizadas as mudanças fundamentadas nos chamados componentes impessoais da didática, entendidos como os conteúdos, os objetivos, os meios, os métodos, a avaliação e as formas de organização do processo de ensinoaprendizagem. Todavia, em meados de $200 \mathrm{I}$, na origem da nova proposta para a ESB cubana, a visão retrospectiva das campanhas de formação emergente indicava que "a essência dos câmbios é a transformação dos professores" (Valle Lima et al., 2003, p.26). O cerne do modelo destacava o papel do professor como educador e as mudanças pretendidas admitiam que o docente não tinha mais o monopólio do saber, devendo a sua função estar centrada em guiar o aluno na busca de conhecimentos. Transformava-se também a relação do professor com a família por meio de novas formas de interação, permanentes e ativas, ante a possibilidade de um trabalho estável, favorecido pelo aprofundamento do vínculo lar-escola e pelas relações afetivas estabelecidas entre alunos e docentes.

Segundo Gómez Gutiérrez (2005), na concepção desse novo educador, acentuou-se o seu envolvimento com meios didáticos que utilizavam tecnologia atual, bem como a imperiosa necessidade de revolucionar esse nível de ensino. Para dar resposta aos problemas que afetavam a qualidade da educação, em particular os relacionados ao trabalho altamente individualizado no processo educativo, implementou-se a formação de professores generalistas integrais, capazes de ministrar todas as disciplinas, exceto Inglês e Educação Física, a um grupo de 15 alunos, convertendo dessa forma o professor em um conselheiro, conhecedor do meio familiar, das perspectivas e dificuldades do aluno. De acordo com a proposta, o professor polivalente deveria acompanhar o mesmo grupo de alunos, da $7^{\text {a }}$ à $9^{a}$ séries, o que lhe asseguraria o conhecimento aprofundado das características dos estudantes, a atenção particularizada aos 
problemas por eles apresentados, além da possibilidade de compartilhar o desenvolvimento da personalidade dos alunos do grupo em cada etapa.

Em 2005, Cuba dispunha de 16 Institutos Superiores Pedagógicos, tendo por objetivo capacitar os professores para todos os níveis do sistema educacional (Cuba, 2005). Dentro do projeto, as sedes universitárias, que congregam os professores dos ISPs e adjuntos, passaram a ser o local em que, aos sábados, os graduandos desenvolvem atividades acadêmicas e recebem orientações voltadas às práticas docentes, sob responsabilidade do Ministério de Educação. O cumprimento do princípio básico da pedagogia cubana de vincular o estudo ao trabalho buscou estar em sintonia com os avanços tecnológicos que invadiram as salas de aula - televisão, vídeo, computador e software - e introduzir mudanças curriculares, além de fomentar a dimensão prática de diversas áreas, não apenas nas classes ou por meio do conteúdo das disciplinas, uma vez que o enfoque laboral do ensino envolve, além de conhecimentos, valores e normas de conduta.

A concepção das escolas secundárias básicas, tratadas como microuniversidades, foi implementada em todas as províncias de Cuba, dentro da chamada Batalla de Ideas, movimento desencadeado com a finalidade de minimizar a desigualdade gerada em consequência do Período Especial. A microuniversidade é um conceito que se fortalece com a proposta de universalização do ensino superior, parte do processo de transformação, que envolve vários subsistemas, dentre eles o de Formação e Aperfeiçoamento do Pessoal Pedagógico. A microuniversidade é uma escola, mas também pode ser um hospital, uma fábrica ou uma oficina, porque essa concepção não é exclusiva da formação do professor, uma vez que pressupõe colocar todos os universitários em contato com a realidade na qual se desenvolve fisicamente a profissionalização. Segundo Alarcón de Quesada (2006), "das 3. 150 sedes municipais, 22 estão instaladas em prisões, as quais foram convertidas em escolas".

No verão de 2001 , tomou-se a decisão de proceder, em caráter experimental, à formação dos PGIs para a educação secundária. "Tratava-se então de formar o docente dentro de uma nova concepção do processo educativo, convertendo-o em detonador das mudanças necessárias" (Rojas Arce, 2005, p.6). Com base em conclusões de pesquisas realizadas na ESB Yuri Gagárin, situada na Província de Havana, e na ESB José Martí, de Havana Velha (p.9), tomou-se a decisão de proceder à formação em massa do novo professor, 
trabalhando com jovens egressos do pré-universitário, que em um ano receberiam a preparação requerida para incorporar-se de maneira direta às práticas docentes. Com mais quatro anos de formação, obteriam o título de Licenciados em Educação, na especialidade Professor Generalista Integral. Ao mesmo tempo, foi necessário preparar os licenciados nas diferentes especialidades, já em exercício, para desempenhar novos papéis, sempre considerando a aceitação voluntária de participar na mudança de perfil. Inserido nessa problemática, o projeto tratou de conciliar, dentro do contexto político-social do país, a formação do professor, harmonizando dois campos que tradicionalmente apresentam uma considerável tensão: o inicial e o contínuo.

Em julho de 2002, o ato de graduação dos primeiros 89 PGls, conhecidos como Los Valientes, configurou-se como uma reedição das campanhas alfabetizadoras da década de 60. Nessa ocasião, foi anunciado que mais 4.500 estudantes ingressariam na Escola Salvador Allende, em Havana, para um novo curso. De acordo com Castro Ruz (2002), a "Allende" era dirigida por um decano, cinco vice-decanos, secretário docente, diretor do Centro de Informação Pedagógica e diretor da Residência Estudantil. $O$ claustro era composto por 412 professores, dos quais 44 eram doutores, 92 mestres, 27 titulares, 60 professores auxiliares e 189 de outras categorias. Dos alunos, 3.242 provinham de institutos pré-universitários no campo, 458 de préuniversitários pedagógicos, 456 de pré-universitários urbanos, 252 de préuniversitários vocacionais e 134 do ensino profissional. Desse total, 2.440 eram filhos de operários, I.252 de profissionais graduados, 695 de camponeses e 155 de militares. Um número elevado deles (57\% do total), mais precisamente 2.575, era membro da União de Jovens Comunistas. $\bigcirc$ curso foi desenvolvido em um ano, com 2.234 horas de formação geral, preparação metodológica e prática docente, além de 72 horas de Educação Física como matéria obrigatória. $O$ centro dispunha de 145 classes com capacidade para trinta alunos, equipadas com computador, TV de 29 polegadas e vídeo; cinco bibliotecas; dez laboratórios de computação com 15 computadores em cada unidade; seis laboratórios de ciências; duas oficinas de educação laboral; dois canais locais de televisão, teatro e ginásio.

Na "Allende", o dia iniciava-se às 7 horas com um "matutino", momento de discussão das notícias locais e do mundo, veiculadas pela televisão na noite anterior. As aulas eram distribuídas entre as disciplinas: Pedagogia, Sociologia, 
Psicologia, Metodologia da Pesquisa, Espanhol, Matemática, História de Cuba e Geral, Geografia, Física, Biologia, Química, Computação, Educação Laboral, Educação Física e Preparação para a Defesa. O curso era em período integral, de segunda a sexta-feira. Aos sábados, as aulas ocorriam até as 13 horas, sendo as tardes destinadas ao descanso e as noites, à recreação. Aos domingos, sob a organização do Departamento de Extensão Universitária, havia visitas aos locais de importância histórica e cultural de Havana, além das participações nas tribunas abertas e galas culturais, para compor os elos entre ensino, pesquisa e extensão. Simultaneamente, em todas as províncias de Cuba, os ISPs formaram, com o mesmo plano de estudos, outros três mil jovens, como PGls emergentes.

Desde o ano letivo de 2002-2003, tornou-se prática usual o modelo de formação docente que, de acordo com Gómez Gutiérrez (2005, p.8), determinava:

- $\quad$ p primeiro ano da carreira universitária, de caráter intensivo, garante a preparação inicial, que permitirá aos estudantes fundamentar sua prática docente na escola.

- Do segundo até o quinto ano da carreira, o PGI/estudante é radicado em uma escola, com a concepção de microuniversidade, na qual os professores com experiência, licenciados em carreiras específicas, se convertem em tutores, responsabilizando-se pela formação do PGI, paralelamente ao preparo acadêmico recebido aos sábados nas sedes universitárias, sob orientação dos ISPs.

Dos cursos de formação de PGI, foram incorporados 12.553 docentes às ESBs, para o ano escolar de 2004-2005. Esse nível de ensino contava, ainda, com a participação de 26.368 professores graduados, que se converteram em PGls. Em agosto de 2005, mais 4.980 professores iniciaram sua formação (Castro Ruz, 2005).

No cotidiano da ESB cubana introduziu-se, maciçamente, o uso da televisão e do vídeo, como forma de elevar a qualidade do ensino, pelo enfoque interdisciplinar, ainda que o protagonismo de toda estratégia educativa devesse, de acordo com o projeto, permanecer nas mãos dos professores. "Deles brotam as máximas que fazem da escola uma via de emancipação ou um simples 
espaço em que 'mal se aprendem' conceitos e operações automáticas”, nas considerações de Medero Hernández e Sánches Medina (2002, p.28).

A televisão educativa, em rede nacional, emite atualmente programas de Geografia, Biologia, Química, Formação de Valores, Educação Artística e Educação Laboral. Os vídeos, disponíveis nas escolas, incluem Espanhol, Matemática, História e Física. A coleção El Navegante, utilizada nas escolas, é composta por dez softwares educativos, que tratam de temas relacionados às disciplinas de Espanhol, Matemática, Inglês, História de Cuba, História Antiga e Média, Educação Artística, Informática e Ciências Naturais, inspirados em uma conceituação integradora de conteúdos do nível secundário. Para o início do ano escolar de 2003-2004, os programas de computação beneficiavam 100\% das matrículas, com 46.290 computadores instalados em unidades de educação básica, incluindo as rurais, para o que foi necessário eletrificar com coletores solares 2.368 escolas, das quais 93 contavam com apenas um aluno, de acordo com Castro Ruz (2003).

O período escolar em tempo integral, nas ESBs, tem início, aproximadamente, às $7 \mathrm{~h} 30 \mathrm{~min}$, e conclusão às $16 \mathrm{~h} 30 \mathrm{~min}$. $O$ objetivo da dupla jornada é oferecer espaços para o tratamento diferenciado a cada aluno. $\bigcirc$ horário escolar, que deve garantir o planejamento de atividades político-ideológicas, docentes, laborais, esportivas, culturais, recreativas, vocacionais e patrióticas, é variável no decorrer do curso, e, durante as aulas de Inglês, Computação, Esportes e Educação Física, os PGIs realizam encontros de orientação com seus tutores.

trabalho de cooperação entre os docentes, com um grupo maior de alunos, assumiu fundamental importância ao se tomar a decisão de generalizar o novo modelo de ESB em todo o país, por não haver suficientes salas de aula para acolher grupos isolados de 15 alunos, como se concebeu na ideia original. Foram criadas classes de trinta ou de 45 alunos, mantendo-se o princípio de um professor responsável pela formação de 15 alunos. Dessa maneira, desenvolveu-se o conceito de trabalho cooperado, a modalidade de organização mediante a qual os PGIs interagem nas tarefas de planificar, organizar e executar o processo educativo. A formação de um coletivo de professores, para direção do processo de ensino-aprendizagem, manifesta-se na presença dialética e singular de cada elemento. Os docentes, diante da possibilidade de atingir um ambiente de interdependência produtiva e colaboração, devem 
procurar desenvolver um "trabalho comum para a distribuição de ações adequadas, visando lidar com as dificuldades" (Rojas Arce, 2005, p. I0).

O processo de entrega pedagógica, como maneira de garantir que, ao transitar pelo sistema, o estudante seja efetivamente atendido em suas dificuldades e receba tratamento apropriado, deve organizar-se com tempo suficiente, propiciando que os professores visitem centros docentes dos seus futuros alunos e conheçam in situ a realidade, podendo melhor adequar o trabalho educativo (García Ramis, 2005). Para esse fim, utiliza-se o "expediente acumulativo do escolar", um relatório escrito, elaborado pelos diversos professores, que acompanham o aluno desde o seu ingresso no sistema formal de educação. Nesse histórico, estão registrados todos os dados significativos do estudante, inclusive as variações de seu estado de saúde, as características do meio familiar, os avanços e peculiaridades no campo da aprendizagem, permitindo, assim, efetuar um encaminhamento para outro docente, com qualidade e rigor, particularmente importante na passagem do nível primário para o secundário; procedimento que tem favorecido o decréscimo da evasão escolar (Cuba, 2004).

\section{UM OLHAR SOBRE A PROPOSTA EM CONSTRUÇÃO}

Conforme este estudo, os processos educativos em Cuba não podem ser entendidos sem o vínculo com as empreitadas históricas que cunharam um imaginário de vertentes desde a época colonial. $O$ caráter cubano emergiu de uma "resistência", consolidada nas lutas, ao longo do século XIX, nas quais pereceu um terço da população da llha na época. Da fala dos envolvidos no processo desta pesquisa, surgiu um sentimento próprio da população cubana propensa a entrelaçar sua trajetória pessoal com a trama histórica do país, a qual oscila entre o passado de lutas, o presente marcado por di culdades e os interrogantes do futuro. A história cubana tem-se encarregado de reforçar o signi cado do autêntico e do genuíno, em contraposição ao colonialismo e ao neocolonialismo "disfarçados de universalidade", no dizer de Fabelo Corzo (2003, p.206). Cada acontecimento traz à luz a reação contra uma pretensa universalidade que vem de fora, reiterando nos cubanos um afã de originalidade e autoctonia.

A formação do professor como militante político tem requerido, além dos saberes docentes, o preparo na qualidade de transmissor dos princípios 
defendidos pelo socialismo. Porém, segundo Machado (199|), as convicções ideológicas não podem ser simplesmente ensinadas, mas devem ser adquiridas pelos sujeitos mediante a interiorização de experiências significativas. Meras ações mecânicas não devem ser encaradas como expressão das convicções no campo das ideologias, se essas não estiverem associadas ao enraizamento de atitudes conscientes. Para Rojas Arce (2002, p.25), a intencionalidade declarada no projeto da ESB cubana é conseguir "um alto nível de ideologização do ensino". Cabe ressaltar a clara negativa ao aspecto comum na maioria das reformas em outros países, marcadas pela descaracterização do cunho ideológico, sob a pretensa "dimensão técnica que, no senso comum, tende a ser percebida como neutra" (Ferretti, 2006, p.242).

A formação de professores configura-se, na realidade cubana, como um problema político, vinculado ao sistema de controle estabelecido entre o poder e o saber. Na construção da identidade profissional, evidencia-se a mediação do discurso oficial. Mais do que isso, trata-se de um processo histórico que reflete as demandas referendadas pela Revolução. Em suma, a formação de professores inscreve-se em uma problemática mais ampla que extrapola as dimensões epistemológicas dos saberes da profissão docente e está entrecruzada com os valores societários decorrentes do processo iniciado em 1959.

As transformações educacionais, em Cuba, não só afetaram as formas de organização da escola e o caráter do trabalho docente, mas também suscitaram modificações na maneira de pensar como se ensina e como se aprende. Segundo Abdalla (2006), não basta impor regras, é preciso buscar estratégias de mudanças, pois as práticas e a cultura escolar não mudam por decreto. O papel docente na condução do processo muda de polo, avançando em direção inversa ao fazer improvisado, passa da mera transmissão compartimentada em disciplina única à concepção de que o aluno aprende de várias formas. Com a reorientação da aprendizagem, complexa e repleta de contradições, o que se fortalece é a necessidade de o professor conhecer cada vez mais os fundamentos de suas práticas, integradas às características de cada aluno e de sua comunidade. Os procedimentos pedagógicos do projeto para a ESB, entre eles a interdisciplinaridade e o protagonismo do aluno, não representam novidades e não há como recusá-los. No século XIX, Varela afirmava que "o bom professor, quanto menos fala, mais ensina" (Buenavilla Recio, 1995, p.89). 
O que parece expressivo na formação dos docentes cubanos é o envolvimento dos especialistas dos ISPs e a sua inserção na dinâmica diária dos centros educativos, pois a noção concreta de coletivo, o trabalho nas sedes universitárias e a própria estrutura das microuniversidades facilitam a partilha de responsabilidades. A luta por uma educação que reconheça e aprecie as singularidades de cada aluno é incompatível com o transitar dos professores por diversas classes, como indica nossa tradição escolar. Neste caso são geradas situações em que, por falta de espaço e tempo, para uma mediação adequada, os educandos são levados, não raramente, ao insucesso em sua aprendizagem. O trabalho docente com grupos de 15 adolescentes, de acordo com o projeto implementado nas ESBs em Cuba, favorece a construção de um ambiente educativo que valoriza e respeita os sujeitos como portadores de histórias e saberes distintos.

Pelo que foi observado na implementação do modelo, existe uma considerável atenção aos conteúdos desenvolvidos pelos PGls, nas teleclasses e nos programas usados em computadores. Entretanto, os PGls formados en la marcha necessitam de crescente preparação no plano teórico-conceitual. Para isso, seria necessária a adoção de estratégias mais coerentes por parte dos ISPs, melhor definição dos enfoques teóricos que orientam as mudanças e diagnósticos sistemáticos que resultem em maior efetividade do trabalho dos tutores, dos professores das sedes, dos conselhos de série e da direção da própria escola, transformada em microuniversidade. É importante observar, tal como adverte Torres (2003, p. 179), que nas reformas educacionais, muitas vezes, o fracasso de determinadas políticas é atribuído à "incapacidade de quem o implementa e não à sua concepção e ao seu desenho".

Encarados nos projetos educacionais como facilitadores da aprendizagem e desenvolvimento, a televisão e o computador já foram apontados como grandes fontes de lazer e informação para a maioria das pessoas ou mesmo responsabilizados pelo "desaparecimento da infância" (Fernandes, Oswald, 2005, p.28). Nessa tumultuada dicotomia inscreve-se a expectativa de canalizar a energia dos meios de comunicação para suprir lacunas no âmbito escolar, em especial, as relacionadas com a manifesta imaturidade de um contingente significativo dos PGls cubanos.

Daí a ideia que a orientação metodológica no uso desses novos instrumentos deve ser mais sistemática e que, em alguns casos, é necessário maior 
aprofundamento na superação técnica de produção do material. Recém-saídos, eles próprios, das turbulências típicas da puberdade, envolvidos num complexo processo de capacitação profissional, que exige a sedimentação de inúmeras técnicas metodológicas e uma carga de conteúdos necessários para atender ao nível de exigência dos pais e alunos, os docentes encontram dificuldades de trabalhar as informações para transformá-las em conhecimento crítico. Sobre os efeitos das novas tecnologias informativas, sobretudo nos setores mais vulneráveis da sociedade: as crianças e os jovens, as inquietações formuladas por pesquisadores, educadores, pais e alunos, reafirmam-se constantemente. Segundo as palavras de Ramos Rivero (2002, p.2), "não poucas vezes o olhar se choca com espelhos multiplicadores da rotina".

Prolongar o tempo de permanência na escola, sem o tratamento adequado das novas tecnologias, pode significar apenas "mais do mesmo", no dizer de Torres (2003, p. 170). São muitos os fatores que precisam conviver em harmonia para que uma transformação avance em termos de qualidade para todos. Numa jornada ampla, em que o cansaço espreita alunos e professores, as limitações materiais são a principal barreira para a implementação de atividades que tornem as ESBs cubanas mais atrativas. Em alguns casos, a insuficiência de cópias dos vídeos apresentados nas aulas não permite melhor adequação dos horários, o que provoca a dispersão entre os alunos.

Do modelo proposto depreende-se que o contato do aluno com o conhecimento é mediado pela relação que as práticas escolares estabelecem com as dimensões socioculturais dos educandos. Rojas Arce (2005) considera que a formação interdisciplinar deve integrar os conteúdos, porém dentro de um processo que valorize a reflexão e as transformações do mundo atual. Nessa perspectiva, o conhecimento interdisciplinar não poderia restringir-se à sala de aula, mas deveria ultrapassar os limites do saber escolar e se fortalecer na medida da amplitude social, constituindo a sua prática uma atitude de cada educador diante do conhecimento. Como aponta Ferretti (2006), a interdisciplinaridade não representa um aporte inovador no meio educacional e tem sido em inúmeras oportunidades defendida por educadores respeitáveis em todo o mundo. Todavia, independentemente dos aspectos pedagógicos positivos, muitas vezes, "corre-se o risco de ser priorizada mais a aplicação dos conhecimentos a situações de caráter instrumental que seu domínio profundo e efetivamente significativo" (p.254). 
A compreensão da interdisciplinaridade como possibilidade de relacionar conteúdos está presente nas práticas o que, sem dúvida, constitui fator de legitimidade relativa da política curricular proposta, elaborada pela rejeição dos métodos tradicionais predominantes na antiga ESB. Entretanto, ainda que os professores evidenciem preocupação quanto à problemática do relacionamento entre as diversas áreas, isso não significa que a aceitação de uma abordagem interdisciplinar, presente nos planos escolares, seja suficiente para permitir a sistematização de ações integradoras, inseridas em uma compreensão da complexidade do conhecimento, que vença obstáculos internos aos próprios sujeitos, decorrentes de sua formação, marcadamente disciplinar. Os PGls percebem, por exemplo, que a Química partilha conteúdos com a Matemática, que, por sua vez, partilha conhecimentos com a Física e a Biologia, evidenciando uma visão restrita, reduzida ao seu nível mais elementar que é a interdisciplinaridade de ilustração, na qual, ao ser trabalhado um tema de determinada disciplina, o professor apenas ilustra com exemplos a que outras disciplinas aquele conteúdo está relacionado (Fazenda, 200I). Porém, nesse particular, cabe ressaltar o fato de os PGls, sempre que possível, transitarem pelas três séries da ESB com a mesma turma de alunos, o que favorece a estruturação horizontal e vertical da reflexão interdisciplinar, a coerência entre pensamento e ação, a superação de visões fragmentadas.

Ao movimento global, pautado pela inauguração de novos projetos a cada gestão, que muitos denominam "onda reformista", pode ser debitado o desperdício de importantes recursos, uma vez que a descontinuidade ignora o esforço empreendido pelos coletivos escolares, o levantamento de dados e a análise de relações do saber historicamente construído. Muitas das reformas pretendidas, em diversos países, não chegam às salas de aula, ou não alteram em profundidade seu cotidiano. As chamadas inovações são introduzidas sem uma avaliação dos erros e avanços das lições que poderiam ser extraídas dos programas que "caíram de moda". A visão retrospectiva da formação docente em caráter emergencial nos diferentes contextos imbricados no processo político-social do país, afasta as transformações na ESB das mudanças que partem do zero, sem recuperar a experiência e as pesquisas disponíveis, desconsiderando as condições reais e específicas das práticas.

Com a globalização, o conflituoso entrelaçamento da escola com o trabalho e sua inserção no campo dos valores aponta a transformação na ESB 
cubana em oposição aos modelos que reduzem a educação a um problema setorial, desprezando o papel da escola na formação do homem. Ainda que antagônica, nas concepções dos países sob a influência do neoliberalismo e no modelo almejado no socialismo -, a escola é valorizada como o locus ideal da concretização dos objetivos no plano político-social. As controvérsias remetem, porém, à ideia dos valores que estão em jogo.

\section{CONSIDERAÇÕES FINAIS}

Nas palavras de Castellanos Simons (200I, p.2), "Cuba está no mundo e com o mundo", sendo parte da sociedade planetária que surgiu com o novo milênio. Portanto a evolução da economia, a passividade imposta aos jovens em seu processo de socialização e a influência de padrões externos, sobretudo da comunidade cubana residente nos Estados Unidos, conformaram um modelo de bem-estar com tendências à mentalidade de consumidor acima da consciência de produtor, problemas que dificultam a consolidação do projeto socialista na esfera educativa. Considerando a deterioração dos princípios identificados com a ética da Revolução, especialmente o coletivismo, verificou-se que os efeitos dessa tensão se apresentam com maior agudeza na adolescência. Consequentemente, produziu-se uma perda no campo dos valores, e o modelo concebido para a ESB, no entender desta pesquisa, busca consolidar um corpo de resistência no qual os coletivos das escolas são orientados ao trabalho na defesa dos princípios do socialismo, no limite das condições materiais e contando com dificuldades de várias ordens.

Considero que a escola tem contribuído acentuadamente para estabelecer, em Cuba, um quadro distinto do nível de desagregação social que marca as grandes metrópoles da América Latina e do Caribe, onde a violência entrópica demonstra como estamos apartados de contextos razoavelmente justos. Na maioria das sociedades, criaram-se fronteiras, opondo integrados e excluídos.

Entendo que a distância entre os grupos em desvantagem social e os que conhecem a filiação, se é que posso assim chamá-los, dentro do formato societário cubano, não inclui a incerteza brutal que nos mantém em estado de alerta contra assaltos à mão armada, sequestros e outras formas de criminalidade frequentes nos países alinhados ao capitalismo da era globalizada. A 
análise não exclui o registro da precariedade de moradias, especialmente nas zonas de grande concentração urbana de Havana, as deficiências no abastecimento de água e energia elétrica, as dificuldades no serviço de transporte e no recolhimento de lixo urbano. As limitações engendradas na crise surgida com o Período Especial não acarretaram, contudo, o abandono de prédios escolares, o fechamento de hospitais, o fenômeno dos "meninos de rua" e de populações excluídas pelo sistema de saúde.

O estudo empreendido permitiu compreender o papel dos sujeitos políticos na construção de alternativas societárias. Diante desse quadro, pondero que a formação de professores não se pode ater apenas ao domínio do conhecimento técnico-instrumental, evidenciado nas inovações circunscritas mais à aquisição de destrezas e menos às dimensões que trabalham relacionalmente com a emancipação dos indivíduos.

No debate mundializado sobre a formação de professores há dois polos a considerar: o professor como agente e a escola como instituição que abarca uma infraestrutura. $\bigcirc$ que me parece significativo na experiência cubana é a preocupação com a pessoa do professor, prioritária e indissolúvel das políticas de melhoria das escolas como espaços concretos. Concordo com Almeida (2006, p.88) que as reformas educacionais aceleram e intensificam os elementos que reconfiguram a profissionalização docente, porque não há transformação possível, se as condições materiais mínimas não estiverem asseguradas.

Ao parafrasear Haug (2002, p.40), "nada é novo e tudo é diferente", acredito ser a constância nos investimentos e a determinação política que o Estado imprime à educação o maior diferencial em relação às reformas realizadas em outros países, ou seja, a intencionalidade das políticas de formação de professores na educação cubana é acompanhada de múltiplas medidas viabilizadoras da dimensão político-epistemológica das transformações pretendidas.

\section{REFERÊNCIAS BIBLIOGRÁFICAS}

ABDALLA, M. F. B.O Senso prático de ser e estar na profissão. São Paulo: Cortez, 2006.

ALARCÓN DE QUESADA, R. La Universalización de la universidad por un mundo mejor. In: ENCUENTRO INTERNACIONAL DE EDUCACIÓN SUPERIOR. La Habana, 2006.

ALMEIDA, M. I. A Reconstrução da profissionalidade docente no contexto das reformas educacionais: vozes de professores na escola ciclada. In: SILVA, A. M. M. et al. (Org.). 
Políticas educacionais, tecnologias e formação do educador: repercussões sobre a didática e as práticas de ensino. Recife: Endipe, 2006. p.83-105.

ANDRÉ, M.E. D. A. Etnografia da prática escolar. Campinas: Papirus, 2004.

BUENAVILLA RECIO, R. et al. Historia da pedagogía en Cuba. La Habana: Pueblo y Educación, 1995.

CASTELLANOS SIMONS, D. et al. Aprender en la escuela: una concepción desarrolladora. La Habana: Instituto Superior Pedagógico Enrique José Varona, 200 I.

CASTRO ALEGRET, P. L. Educación y equidad: el trabajo de la escuela con niños y familias en situaciones de desventaja social. In: PEDAGOGÍA 2005. Resumen. La Habana, 2005.

CASTRO RUZ, F. Discurso pronunciado. In: ACTO DE GRADUACIÓN DE LA SECUNDARIA BÁSICA JOSÉ MARTí, 23 jul. 2005. Granma, n.6 (esp.), p.3, 2005.

. Discurso pronunciado. In: ACTO DE INAUGURACIÓN DEL CURSO DE FORMACIÓN EMERGENTE DE PROFESORES INTEGRALES DE SECUNDARIA BÁSICA, 9 set. 2002. Disponível em: http://www.cuba.cu/gobierno/discursos/. Acesso em: 10 set. 2005.

. Discurso pronunciado. In: ACTO DE INAUGURACIÓN OFICIAL DEL CURSO ESCOLAR DE 2003-2004, 8 set. 2003. Disponível em: http://www.cuba.cu/ gobierno/discursos/. Acesso em: 10 set. 2005.

CHÁVEZ RODRÍGUEZ, J. Las Ideas de José Martí sobre educación. In: TURNER, L. et al. Martí y la educación. La Habana: Pueblo y Educación, 1996. p.35.

CUBA (República de). Ministerio de Educación. El Desarrollo de la educación en Cuba. Informe Nacional. La Habana, 2004. Disponível em: http://www.oei.es/quipu/cuba/ ibecuba.pdf. Acesso em: fev. 2008.

. La Educación en Cuba. In: PEDAGOGÍA 99: ENCUENTRO POR LA UNIDAD DE LOS EDUCADORES. La Habana, 1999.

. Informe 2005. Disponível em: http://www.rimed.cu/pedagogicos.asp\#. Acesso em: 12 set. 2005.

DÍAZ FUENTES, F. El Cambio en secundaria básica: un proyecto de nuevo tipo. In: PEDAGOGÍA 2005. Resumen. La Habana, 2005.

FABELO CORZO, J. R. Los Valores y sus desafíos actuales. La Habana: José Martí, 2003.

FAZENDA. I. C. A. (Org.). Práticas interdisciplinares na escola. 8.ed. São Paulo: Cortez, 2001 . 
FERNANDES, A. H.; OSWALD, M. L. B. M. A Recepção dos desenhos animados da TV e as relações entre a criança e o adulto: desencontro e encontros. Cadernos do Cedes, Campinas, v.25, n.65, p.43-58, jan./abr. 2005.

FERRETTI, C. J. A Educação profissional e as novas exigências na formação de professores e nas práticas pedagógicas: uma análise crítica. In: SILVA, A. M. M. et al. (Org.). Políticas educacionais, tecnologias e formação do educador: repercussões sobre a didática e as práticas de ensino. Recife: Endipe, 2006. p.241-257

GARCÍA RAMIS, L. Un modelo de escuela y de currículo para la secundaria básica cubana actual: fundamentos pedagógicos. In: PEDAGOGÍA 2005. Resumen. La Habana, 2005.

GÓMEZ GUTIÉRREZ, L. I. Cuba: una revolución en la educación. In: PEDAGOGíA 2005: ENCUENTRO POR LA UNIDAD DE LOS EDUCADORES. La Habana, 2005.

HAUG, W F. Nada es nuevo y todo es diferente. Revista Internacional Marx Ahora, La Habana, n. I3, p.40-52, 2002.

LEITE, M. C. C. Los Valientes: a formação de professores na escola secundária básica em Cuba. 2006. Disssertação (Mestrado em Educação) - Universidade Católica de Santos, Santos.

MACHADO, L. R. de S. Socialismo, trabalho e educação: o trabalho como princípio educativo em Cuba. 1991. Tese (Livre-Docência) - Universidade Federal de Minas Gerais, Belo Horizonte.

MARTÍ, J. Obras completas. La Habana: Ciencias Sociales, 1975.

MARTÍNEZ LIMA, M. José Martí: autor intelectual de la batalla de ideas. Disponível em: http://www.monografias.com/trabajos I 5/marti-ideas/marti-ideas.shtml. Acesso em: 2 l out. 2005.

MEDERO HERNÁNDEZ, N; SÁNCHES MEDINA, M. Maestro, comunicador, sensibilizador. Revista Educación, La Habana, n. I07, p.45-49, sept./dic. 2002.

RAMOS RIVERO, P. Las Otras ventanas de la aula. Revista Educación, La Habana, n. I07, p.2-13, sept./dic. 2002.

ROJAS ARCE, C. La Experiencia cubana en la realización del cambio educativo en la secundaria básica. In: PEDAGOGíA 2005. Resumen. La Habana, 2005.

Informe de la investigación de seguimiento de las transformaciones en las secundarias básicas de Ciudad de La Habana. La Habana: Instituto Superior Pedagógico Enrique José Varona, 2002. 
TORRES, R. M. Melhorar a qualidade da educação básica? As estratégias do Banco Mundial. In: TOMMASI, L. de; WARDE, M. J.; HADDAD, S. (Org.). O Banco Mundial e as políticas educacionais. 4.ed. São Paulo: Cortez, 2003. p. I25-186.

VALLE LIMA, A.et al. La Transformación educativa: consideraciones. La Habana: Pueblo y Educación, 2003.

Recebido em: agosto 2007

Aprovado para publicação em: março 2008 